\title{
EXIGÊNCIA NUTRICIONAL DE VITAMINA A PARA ALEVINOS \\ DE TILÁPIA DO NILO Oreochromis niloticus
}

\section{DANIELA FERRAZ BACCONI}

\begin{abstract}
Dissertação apresentada à Escola Superior de Agricultura "Luiz de Queiroz", Universidade de São Paulo, para obtenção do título de Mestre em Agronomia, Área de concentração: Ciência Animal e Pastagem.
\end{abstract}

P I R A C I C A B A

Estado de São Paulo - Brasil

Maio - 2003 


\section{EXIGÊNCIA NUTRICIONAL DE VITAMINA A PARA ALEVINOS \\ DE TILÁPIA DO NILO Oreochromis niloticus}

\section{DANIELA FERRAZ BACCONI \\ Bióloga}

\section{Orientador: Prof. Dr. JOSÉ EURICO POSSEBON CYRINO}

Dissertação apresentada à Escola Superior de Agricultura "Luiz de Queiroz", Universidade de São Paulo, para obtenção do título de Mestre em Agronomia, Área de Concentração: Ciência Animal e Pastagem.

P I R A C I C A B A

Estado de São Paulo - Brasil

Maio - 2003 


\section{Dados Internacionais de Catalogação na Publicação (CIP)} DIVISÃO DE BIBLIOTECA E DOCUMENTAÇÃO - ESALQ/USP

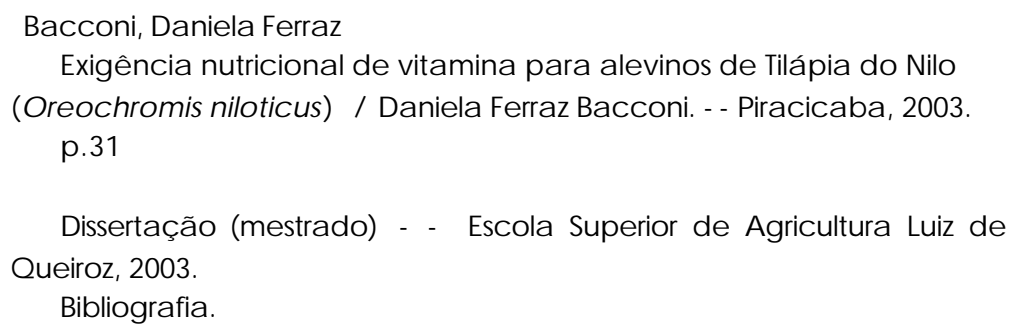

1. Alevino 2. Exigência nutricional 3. Vitamina A 4. Tilápia do Nilo I. Título

CDD 639.31 
Aos meus pais, Wagner e Délia pelo apoio, exemplo de luta e criação. Aos meus irmãos, Nana e Douglas que sempre estão comigo. Amo vocês.

OFEREÇO

"Feliz o homem que acha sabedoria, e o homem que adquire conhecimento"

Provérbios 3:13 


\section{AGRADECIMENTOS}

A Deus, criador de todo o universo, detentor de todas as respostas, a quem eu dou Glórias e Graças por toda a sabedoria que me proporcionou neste trabalho. A Ele seja dado todo o Louvor, Adoração e Poder.

Ao Departamento de Zootecnia da ESALQ/USP, pela acolhida e apoio oferecido durante a realização do curso.

Ao Prof. José Eurico Possebon Cyrino, pela oportunidade, amizade, orientação e confiança em mim depositada durante a realização deste trabalho.

A Fundação de Amparo à Pesquisa do Estado de São Paulo, FAPESP, pela concessão da bolsa de estudo.

À Piscicultura Bela Vista pela doação dos alevinos utilizados no experimento.

À Supre Mais pela doação das misturas de vitaminas e minerais e também pela vitamina A, imprescindíveis na realização do trabalho.

À Profa. Helena Teixeira Godoy ao doutorando Rodrigo Ramos Catharino da Faculdade de Engenharia de Alimentos - UNICAMP, pela realização das análises.

Aos amigos e colegas de setor Leandro, Ana Maria, Andréa, Geraldo, Luciane, Ana Cristina, Anderson, Jony, Sílvio, Hermann, Paulo, André Luiz e Jussiara, que contribuíram com meu trabalho e com minha formação profissional. Obrigada!

Aos funcionários do Setor de Piscicultura, Ismael Baldessin Júnior e Sérgio Vanderlei Pena, que foram imprescindíveis na realização deste trabalho. Obrigada! 
Às amigas sempre presentes Lirís, Andréinha, Daniela, Priscila e Juliana.

Aos demais colegas e do Departamento de Zootecnia por todo o apoio, especialmente Juliana Giannotti e Cláudia Paz, pelo auxílio nas análises estatísticas.

A todos os meus familiares que sempre torcem por mim e também estão comigo em todos os momentos.

Aos amigos da Biologia da USP Ribeirão Preto que sempre estarão presentes na minha vida.

Ao Luís Fernando, melhor amigo e companheiro que Deus poderia me presentear para toda a vida.

A todos que de alguma forma contribuíram para a realização deste trabalho. 


\section{SUMÁRIO}

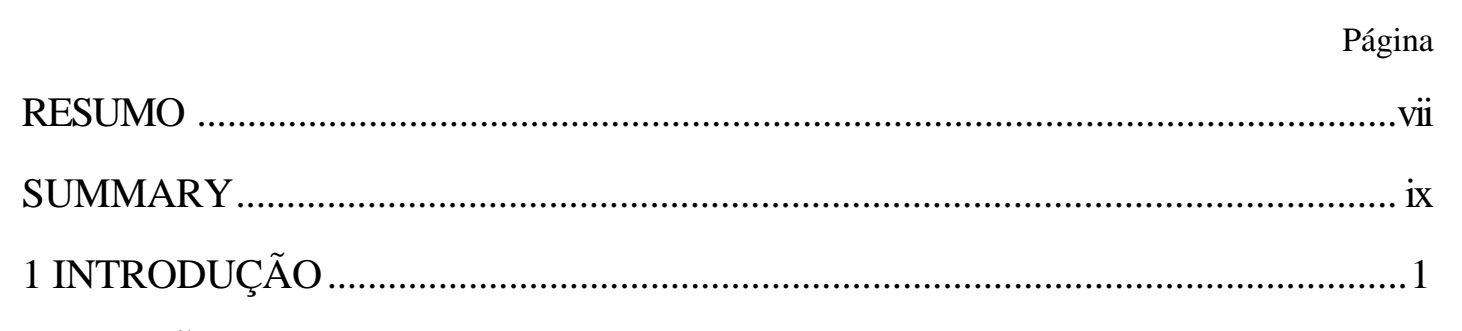

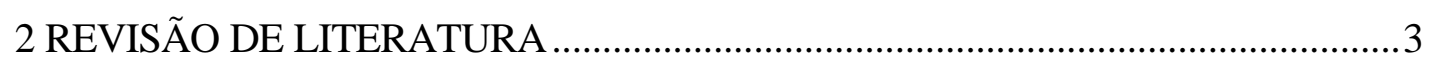

2.1 Nutrição na piscic ultura .................................................................................

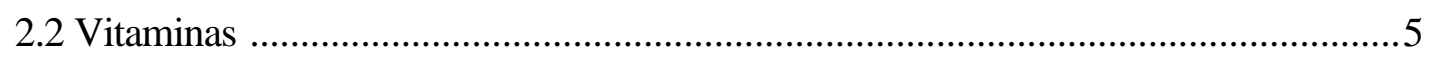

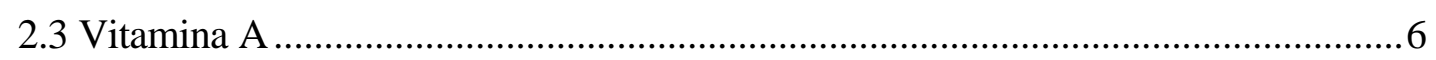

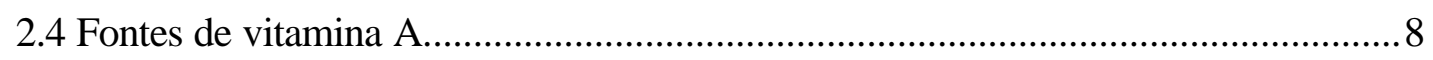

2.5 Deficiência de vitamina A e hipervitaminose A .....................................................

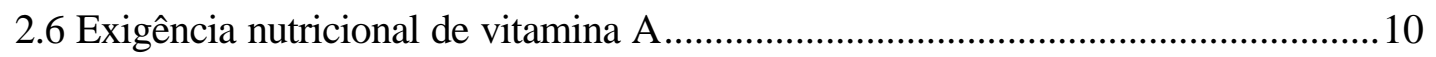

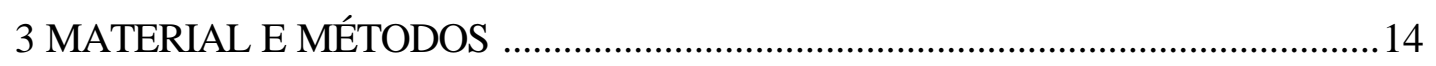

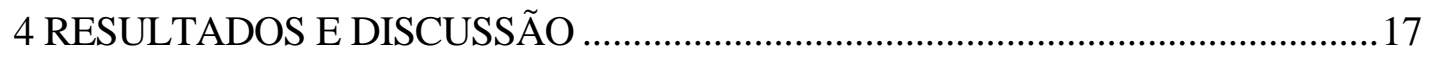

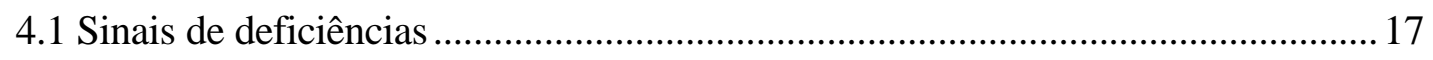

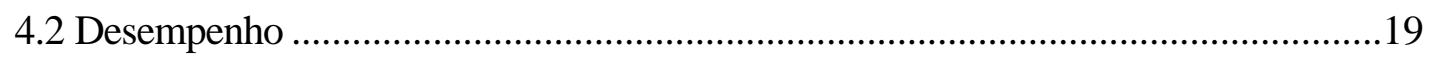

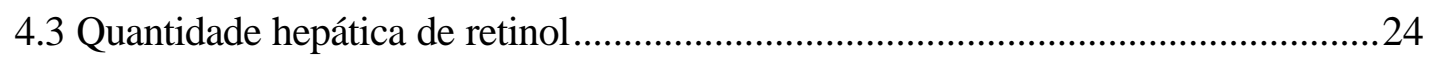

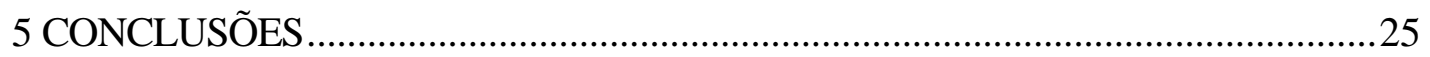

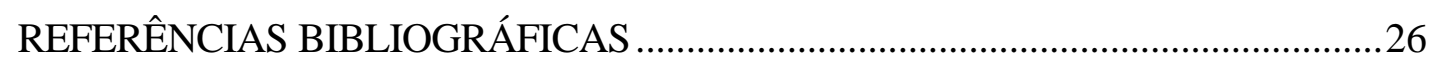




\title{
EXIGÊNCIA NUTRICIONAL DE VITAMINA A PARA TILÁPIA DO NILO Oreochromis niloticus
}

\author{
Autora: DANIELA FERRAZ BACCONI \\ Orientador: Prof. JOSÉ EURICO POSSEBON CYRINO
}

\section{RESUMO}

O excesso de vitaminas lipossolúveis na dieta pode ser acumulado no fígado e causar hipervitaminose em animais. Os objetivos deste trabalho foram determinar a exigência nutricional em vitamina A para juvenis da tilápia do Nilo Oreochromis niloticus, avaliar o desempenho da espécie através do ganho de peso e conversão alimentar e quantificar os depósitos de retinol hepático em animais de uma população revertida sexualmente para o sexo masculino $(\mathrm{R} ; 13,76 \pm 1,21 \mathrm{~g})$ e outra não revertida $(\mathrm{NR} ; 9,83 \pm 2,30 \mathrm{~g})$. Os peixes foram estocados em aquários de polipropileno de $100 \mathrm{~L}$, em ambiente com condições controladas de temperatura $\left(25,0 \pm 1,0{ }^{\circ} \mathrm{C}\right)$ e luminosidade (12h00m:12h00m), e alimentados ad libitum duas vezes ao dia, durante 75 dias, com dietas semipurificadas, suplementadas com 0; 600; 1200; 1800; 2400; 3000; 3600; 4200; 4800 e 5400 UI kg ${ }^{-1}$ de dieta de retinil palmitato (Rovimix A 500 Roche $^{\circledR}$ ), em delineamento experimental inteiramente casualizado em esquema fatorial $2 \times 10 \quad(n=4)$. Ao final do experimento todos os lotes de animais foram sacrificados para a análise de retinol hepático. Sinais severos de deficiência nutricional em vitamina A foram encontrados em animais dos tratamentos 0; 600 e 1200 UI vitamina $\mathrm{A} \mathrm{kg}^{-1}$ de dieta; sinais moderados foram também encontrados em animais dos tratamentos entre $1800 \mathrm{e}$ 
3600 UI vit $\mathrm{A} \mathrm{kg}^{-1}$ de dieta, em ambos os grupos. As interações grupo*nível não foram significativas $(\mathrm{P}<0,05)$ para todas as variáveis de desempenho analisadas. Níveis crescentes de inclusão da vitamina A influenciaram o peso final e ganho de peso dos peixes $(\mathrm{P}<0.05)$, mas não influenciaram o consumo de ração $(\mathrm{P}>0,05)$. Houve um efeito de grupo para todas as variáveis analisadas $(\mathrm{P}<0,0001)$. A análise cromatográfica somente detectou depósitos de vitamina A no fígado dos animais alimentados com a dieta contendo $5400 \mathrm{UI} \mathrm{kg}^{-1}$ de retinol. 


\title{
DIETETIC VITAMIN A REQUIREMENTS OF NILE TILAPIA Oreochromis niloticus
}

\author{
Author: DANIELA FERRAZ BACCONI \\ Adviser: Prof. JOSÉ EURICO POSSEBON CYRINO
}

\section{SUMMARY}

Excess dietary fat-soluble vitamins can be accumulated in the liver and cause hypervitaminosis in animals. The aim of this research was to establish the vitamin A requirement for Nile tilapia Oreochromis niloticus, evaluating weight gain and food conversion ratio, and quantifying hepatic retinol deposits in a sex reversed, all male population $(\mathrm{R} ; 13.76 \pm 1.21 \mathrm{~g})$ and a mixed sex population $(\mathrm{NR} ; 9.83 \pm 2.30 \mathrm{~g}$ ). Fish were stocked in 100-L plastic aquaria, in controlled environmental conditions of temperature $\left(25,0 \pm 1,0^{\circ} \mathrm{C}\right)$ and luminosity $(12 \mathrm{~h} 00 \mathrm{~m}: 12 \mathrm{~h} 00 \mathrm{~m})$, and fed ad libitum, twice a day, seven days a week, during seventy five days with semi-purified diets supplemented with $0 ; 600 ; 1,200 ; 1,800 ; 2,400 ; 3,000 ; 3,600 ; 4,200 ; 4,800$ and 5,400 IU of retinol palmitate per $\mathrm{kg}$ of diet (Rovimix A 500 Roche ${ }^{\circledR} ; 30 \%$ vitamin A) in a totally randomized experimental design, factorial arrangement $2 \times 10(n=4)$. At the end of the experiment all groups were sacrificed and liver tissue excised for the hepatic retinol analyses. Severe signs of nutritional deficiency of vitamin A were observed in fish of treatments $0 ; 600$ and 1,200 IU vitamin $\mathrm{A} \mathrm{kg}^{-1}$ diet; moderate signs were also found in fish of treatments 1,800 trough 3,600 IU vitamin $\mathrm{A} \mathrm{kg}^{-1}$ diet, both populations. Interactions group*level were not significant $(\mathrm{P}<0.05)$ to all analyzed performance 
variables. Increasing levels of dietary vitamin A influenced final weight and weight gain of the fish $(\mathrm{P}<0.05)$, but did not influence feed consumption $(\mathrm{P}>0.05)$. A group effect was observed regarding all performance variables $(\mathrm{P}<0.0001)$. Hepatic retinol quantification (High Performance Liquid Chromatogaphy) detected vitamin A only in fish fed 5,400 IU of retinol per $\mathrm{kg}$ of diet. 


\section{INTRODUÇÃO}

A espécie Oreochromis niloticus (L.) - tilápia do Nilo - é originária da África e foi introduzida no Brasil em 1971 (Lovshin, 2000). A sustentabilidade ambiental, prolificidade e rusticidade da espécie são características que favorecem sua criação da em todo o mundo. Trata-se de uma espécie cosmopolita, com bom índice de crescimento e alta resistência a doenças.

A tilápia do Nilo é criada desde o sistema extensivo até os mais modernos sistemas superintensivos, em tanques, viveiros, gaiolas ou tanques rede. Lovshin (2000) considera que a produção de tilápias no Brasil varie entre 20 a 25 mil t anuais. Castagnolli (2002) relata que pelo menos 10 a 15 mil t de tilápias são produzidas no Brasil anualmente, a partir de alimentos e resíduos da produção animal obtidos nas propriedades.

Em sistemas comerciais de criação de tilápias, nos quais o alimento natural é restrito, é absolutamente necessário utilizar rações completas de alta qualidade. As proteínas de origem vegetal utilizadas na composição de rações comerciais são mais baratas que aquelas de origem animal (Fitzsimmons, 2000). Por outro lado, as fontes protéicas dietéticas de origem animal, mesmo em menores percentagens, garantem e melhoram o valor nutritivo das dietas, em função do melhor balanço em aminoácidos, minerais e vitaminas do complexo B que possuem (Pezzato, 2002).

Criadores de tilápias de todo o mundo utilizam produtos regionais, ou mesmo subprodutos de suas próprias plantações, para alimentar suas criações (Tacon, 1994; Adesulu \& Mustapha, 2000). A elaboração deste tipo de dieta é possível devido à grande viariedade de alimentos que as tilápias são capazes de digerir, diminuindo o custo de produção. Por outro lado este tipo de dieta não garante o balanço de nutrientes exigido 
para um bom desempenho em criações intensivas. Entre os nutrientes exigidos destacam-se as vitaminas que são essenciais na diminuição do estresse causado pela alta densidade, e na regulação do sistema imunológico dos animais.

As vitaminas, consideradas micronutrientes nas rações, são importantes cofatores ou substratos de reações enzimáticas e possuem funções catalíticas específicas nos processos metabólicos celulares (Steffens, 1989). Quantidades inadequadas de vitaminas nas dietas podem resultar em doenças relacionadas à nutrição, crescimento reduzido ou aumento da susceptibilidade a infecções (Hepher, 1988; NRC, 1993; de Silva \& Anderson, 1995). Como exemplo, deficiência de vitamina A na dieta do salmão cereja Oncorhynchus masou resulta na diminuição na taxa de crescimento e sobrevivência (Taveekijakarn, 1994). Crescimento anormal das vértebras, redução dos depósitos de gordura e do tamanho do fígado são exemplos de sinais de hipervitaminose A em larvas de salmão do Atlântico Salmo salar (Ornsrud et al., 2002).

Vitaminas lipossolúveis (A, D, E e K) são armazenadas nos depósitos de lipídios hepáticos, especialmente quando a quantidade de vitamina ingerida não é totalmente utilizada pelo organismo do peixe (NRC, 1993). Com base nestas considerações, o objetivo deste trabalho foi determinar a capacidade de armazenamento de vitamina A no fígado da tilápia do Nilo através da quantificação do retinol armazenado no óleo hepático e determinar a exigência nutricional em vitamina A para juvenis da espécie através da avaliação do desempenho produtivo e nutricional. 


\section{REVISÃO DE LITERATURA}

\subsection{A nutrição dos organismos aquáticos}

Como qualquer outro animal os peixes necessitam de proteínas, minerais, fontes de energia e vitaminas para um bom desenvolvimento e crescimento. Alimentar animais aquáticos implica em relevar a contribuição de alimento natural encontrado no ambiente, o efeito da ração na qualidade da água e na perda de nutrientes se o alimento não é consumido imediatamente (Lovell, 1991). Entretanto, quando em sistema de criação intensivo ou super-intensivo, onde o alimento natural é restrito e o consumo de alimento é rápido, o peixe necessita de uma dieta nutricional balanceada e completa. É essencial, nestes casos, que as dietas contenham suplementação vitamínica e mineral (Lovell, 1989; 1998).

Peixes utilizam proteína como principal fonte de energia, por isso a quantidade de proteína exigida para a dieta de peixes é muito superior à exigida para outros animais (Lovell, 1991). A quantidade de proteína exigida na dieta de peixes varia com o hábito alimentar, fase de desenvolvimento e condição de criação. De modo geral, dietas práticas para peixes onívoros confinados devem incluir 30\% a 35\% de proteína que apresente bom balanço de aminoácidos. Os peixes necessitam dos mesmos dez aminoácidos essenciais que necessitam os animais homeotérmos. A quantidade de proteína em dietas para peixes carnívoros é de aproximadamente 40\% (Lovell, 1991). Tilápias, que são onívoras, necessitam de $28 \%$ a $32 \%$ de proteína, mas na fase larval esta exigência sobe para 30\% a 47\% (Luquet,1991).

Proteína da soja é mundialmente utilizada na composição de dietas para peixes por ser praticamente completa na composição de aminoácidos essenciais e mais barata 
do que a proteína de origem animal, como exemplo a farinha de peixes. Contudo para ao criação de peixes carnívoros é necessária a inclusão de proteína animal, que não só é mais palatável, mas também proporciona melhor desempenho das espécies produzidas em função do perfil de aminoácidos mais adequado às suas exigências (Lovell, 1991).

Peixes têm baixa necessidade de alimentos energéticos em sua dieta, em função da pouca quantidade de energia gasta para manter sua posição no ambiente e para se mover na água, em comparação aos mamíferos e aves, e também porque excretam nitrogênio na forma de amônia, perdendo menos energia no catabolismo protéico e na excreção do composto nitrogenado. Peixes utilizam principalmente proteínas e triglicerídeos como fontes de energia (Lovell, 1991). Tilápias utilizam bem a energia consumida na forma de carboidratos. As taxas de inclusão deste nutriente para a dieta de tilápia pode variar de 35\% a 85\% (Luquet, 1991).

Peixes podem obter minerais como $\mathrm{Ca}$ e $\mathrm{P}$, da água através das brânquias. Contudo, a quantidade de $\mathrm{P}$ encontrada na água não é o suficiente para suprir as necessidades metabólicas dos peixes. Assim sendo, a suplementação na dieta se torna essencial (Lovell, 1991). A determinação da exigência de minerais em tilápias é relativamente difícil porque em função do seu hábito alimentar filtrador, a espécie pode absorver minerais da água (Luquet, 1991).

As vitaminas são de essencial importância para a dieta de peixes porque estão envolvidas em $100 \%$ das reações metabólicas encontradas nestes animais. As vitaminas hidrossolúveis têm sido mais estudadas, pois estão diretamente envolvidas nos casos de estresse e doenças causados nos peixes. Pelo menos quinze vitaminas são essenciais na dieta de peixes, mas não são todas as espécies de peixes que necessitam das mesmas quinze. As exigências em vitaminas estão determinadas com relativa precisão e detalhes para bagre do canal, salmonídeos e carpa. Normalmente, as rações produzidas comercialmente são suplementadas com todas as vitaminas. A quantidade varia de acordo com o hábito alimentar (Lovell, 1991; NRC, 1993).

Os resultados das determinações de vitaminas em alimentos feitas em laboratório são utilizados pelas fábricas de ração comercial no processo de adição de vitaminas em seus produtos, mas a quantidade natural de vitaminas encontradas nos 
outros ingredientes e a possibilidade do animal forragear no viveiro, não são levadas em consideração. Por exemplo, Kubitza et al. (1998) e Kubitza e Cyrino (1999) observaram que rações comerciais brasileiras para peixes tropicais onívoros podem conter níveis de vitamina A variando entre 3.000 e $22.000 \mathrm{UI} \mathrm{kg}^{-1}$ de dieta.

\subsection{Vitaminas}

Vitaminas são moléculas orgânicas que agem como cofatores ou substratos em algumas reações metabólicas, desempenhando funções específicas nos processos metabólicos celulares com função catalítica (Steffens, 1989). São exigidas em microquantidades de fontes exógenas (normalmente o alimento) para o crescimento, reprodução e saúde normais (NRC, 1993). A deficiência ou a hipovitaminose referente a uma determinada vitamina, causa uma síndrome de deficiência específica. A definição de vitamina pode ser entendida como tendo referência específica para a espécie de animal, estágio de desenvolvimento, condição dietética e nutricional e condições físicas do ambiente. Alguns compostos são vitaminas para uma espécie e para outras não, a exemplo da vitamina $\mathrm{C}$ para humanos e peixes. Alguns outros compostos são vitaminas somente sob condições dietéticas ou ambientais específicas (Combs, 1992).

Poucas das vitaminas são substâncias únicas; quase todas são famílias de substâncias químicas relacionadas, isto é, dividindo qualitativamente atividades biológicas. Então, o nome comum de uma vitamina é, na verdade, uma descrição genérica para todos os compostos de um grupo que têm a mesma atividade biológica (Combs, 1992).

As vitaminas são divididas em hidrossolúveis e lipossolúveis. Normalmente as vitaminas hidrossolúveis funcionam como coenzimas, já as vitaminas lipossolúveis têm funções independentes das enzimas (NRC, 1993). As vitaminas lipossolúveis são formadas primariamente por unidades de cinco carbonos isoprenóides derivados inicialmente de acetil-CoA nas plantas ou animais capazes de sua biossíntese. Entretanto, as vitaminas hidrossolúveis têm, em geral, poucas similaridades de estrutura. 
As rotas de suas biossínteses, nas espécies capazes de sintetizá-las, não compartilham dos mesmos caminhos bioquímicos (Combs, 1992).

As exigências em vitaminas para a maioria das espécies de organismos aquáticos produzidos comercialmente em confinamento ainda não foram determinadas. Assim sendo, os resultados obtidos em estudos com salmonídeos, carpa e bagres são normalmente aplicados para as outras espécies (De Silva e Anderson, 1995). Contudo a resposta de várias espécies de peixes a diferentes vitaminas pode ser diferente, e portanto as exigências em vitaminas podem também variar (Hepher, 1988)

$\mathrm{Na}$ piscicultura intensiva, é necessário adicionar às dietas um suplemento vitamínico que garanta uma diminuição na taxa de estresse causado pela alta densidade (Davis et al., 1998; Halver, 1985; Toguyeni et al, 1997). Por outro lado, Davis et al. (1998) constataram que bagres do canal, Icatalurus punctatus, estocados numa densidade de $25000 \mathrm{ha}^{-1}$ e alimentados com dietas contendo níveis reduzidos das vitaminas C, niacina, riboflavina, ácido pantotênico, piridoxina ou tiamina, ou simplesmente com a quantidade de suplemento vitamínico reduzido, não apresentaram variações na quantidade de cortisol sérico.

Se uma determinada vitamina for adicionada em excesso a um alimento pode causar hipervitaminose nos animais que receberem este alimento. Hipervitaminose é normalmente causada pelo excesso de vitaminas lipossolúveis, as quais são difíceis de serem excretadas, sendo armazenadas no fígado pelos animais se a ingestão alimentar exceder a necessidade metabólica. Por outro lado, se determinada vitamina for fornecida em quantidade insuficiente, pode causar doenças nutricionais e crescimento reduzido. As vitaminas lipossolúveis são absorvidas ao longo do intestino delgado junto com os lipídios provenientes dos alimentos; condições favoráveis para a absorção de gorduras também aumentam a absorção de vitaminas lipossolúveis (NRC, 1993).

Deficiências nutricionais em vitaminas aparecem principalmente nos sistemas intensivos, nos quais a densidade de estocagem de peixes é alta e a alimentação suplementar é a maior, senão única, fonte de alimento (Hepher, 1988; Pezzato, 1997; Fracalossi, 1998). Entretanto, cada espécie apresenta uma necessidade quantitativa diferente de cada fonte nutricional. As diferenças nas necessidades em vitaminas entre as 
diferentes espécies de peixes ocorrem porque algumas espécies sintetizam certas vitaminas e também porque cada espécie tem uma resposta diferente a uma determinada quantidade de vitamina (Hepher, 1988; Lovell, 1989; 1998). Estas exigências são espécie-específicas e variam com o tamanho dos peixes, fatores ambientais, idade e estado de maturação do animal, e relações entre nutrientes e fatores ambientais (NRC, 1993; Davies, 1998; Halver, 1985).

As exigências nutricionais em vitaminas para máximo crescimento sob condições ótimas podem ser aumentadas de 3 a 10 vezes sob outras condições como estresse, doenças e interação social (Davis et al., 1998; Halver, 1985; Toguyeni et al, 1997). Crescimento reduzido e aumento da mortalidade são sinais comuns da falta de vitaminas. Entretanto, outros sinais clínicos como perda de apetite, descoloração da pele, perda de coordenação, nervosismo, hemorragias, lesões, fígado com grânulos de gordura e aumento à susceptibilidade a infecções bacterianas podem ser observados em peixes com deficiências nutricionais em vitaminas (Davis et al., 1998; Hepher, 1988).

Aminoácidos, várias vitaminas e nutrientes inorgânicos em geral são relativamente instáveis ao aquecimento, umidade e oxidação que ocorrem sob processos normais de processamento das rações e de armazenamento. Algumas vitaminas estão sujeitas a perdas consideráveis no processo de produção de alimentos, e em geral utilizadas em quantidades maiores do que a exigida (NRC, 1993). Também devido à incerteza do conteúdo e biodisponibilidade das vitaminas nos ingredientes que compõe as rações, as exigências em vitaminas são, na maioria das vezes, atendidas pela adição de um suplemento vitamínico contendo quantidades excessivas de vitaminas.

\subsection{Vitamina A}

Vitamina A é um termo genérico que designa qualquer composto que possui atividade biológica de retinol (Blomhoff, 1994). O primeiro passo na transformação do $\beta$-caroteno em vitamina A é uma clivagem oxidativa para produzir all-trans-retinal, o qual é então reduzido a retinol (Ong, 1994). Tilápias convertem o retinol dietético em 3 dehidroretinol e retinal em 3-dehidroretinal, na mucosa intestinal. Foi demonstrado que 
os carotenóides $\beta$-caroteno e cantaxantina podem ser biotransformados no fígado da tilápia em vitamina $A_{1}$ e que dehidrocarotenóides, tal como astaxantina, zeaxantina, luteína e tunaxantina, são diretamente convertidos em vitamina $\mathrm{A}_{2}$ (Katsuyama e Matsuno, 1988). Esta última forma de vitamina A é encontrada em tecidos frescos de peixes de água doce (AVC, 1966; Halver, 1985; Steffens, 1989; NRC, 1993). Segundo Amar et al. (2001) é muito provável que a conversão de $\beta$-caroteno em vitamina A seja maior quando há deficiência da mesma vitamina no animal.

$\mathrm{O}$ ácido retinóico, que é o último derivado da vitamina $\mathrm{A}$, tem efeito direto no desenvolvimento da morfologia das células cone horizontais presente nos olhos dos peixes (Weiler et al., 1997; Weiler et al., 2000). Observando os efeitos da administração de ácido retinóico (100 mg kg ${ }^{-1}$ ) na dieta sobre a composição corporal de Pagrus major, Ogata e Oku (2001) concluíram que os grupos de animais que ingeriram menores quantidades de retinil acetato ou menores concentrações de ácido retinóico $-10 \mathrm{mg} \mathrm{kg}^{-1}$ de dieta - apresentaram maior incidência de indivíduos com peso corporal abaixo da média. Animais alimentados com dietas contendo $100 \mathrm{mg} \mathrm{kg}^{-1}$ de ácido retinóico na dieta tiveram a capacidade de deposição de lipídios do tecido adiposo aumentada consideravelmente.

A vitamina $\mathrm{A}$ e seus derivados têm ácido retinóico em quantidades potenciais para atuar como morfógenos. Retinóides têm efeitos profundos na regeneração de perna de anfíbios, efeitos estes dependentes da concentração dietética do pigmento, do tempo de administração e do estágio do animal (Maden, 1994). No linguado japonês Paralichthys olivaceus, além de estar envolvido com o desenvolvimento das nadadeiras dos animais, o ácido retinóico estimula o desenvolvimento de cromatóforos durante a metamorfose (Miwa \& Yamano, 1999).

Há também duas formas estereoisoméricas da vitamina, "trans-vitamina A" e "neo-vitamina A", esta última ocorrendo na extensão de 30\%-40\% em óleos de peixes e concentrados sintéticos. As propriedades químicas e atividades biológicas destas duas formas de vitamina são parecidas e, de alguma forma, elas diferem nas características de absorção espectrofotométrica (AVC, 1966). 
Fazendo parte do grupo das vitaminas lipossolúveis, a vitamina A tem como principal função ser componente da proteína rodopsina, um pigmento que absorve luz, encontrado na retina do olho. A vitamina A é exigida pelos vertebrados para a regeneração da rodopsina na retina, e carotenóides são responsáveis pela pigmentação amarelada da córnea de peixes da família dos ciclídeos de hábito diurno (Muntz, 1981). A concentração deste pigmento é responsável pela adaptação dos espécimes à quantidade de luz presente nos diferentes habitats, bem como para o crescimento, reprodução, resistência à infecção, e para manter a secreção diferenciada do epitélio e da mucosa (Landolt, 1989; Steffens, 1989; NRC, 1993).

No caso específico dos peixes, $90 \%$ da vitamina A armazenada é encontrada no fígado; os outros $10 \%$ estão divididos entre olhos, plasma, gordura e aparelho reprodutivo (Katsuyama e Matsuno, 1988). De modo geral, a vitamina A é encontrada somente em animais e pode ser isolada da fração não saponificável de suas gorduras, sendo encontrada em grande quantidade no fígado (AVC, 1966; Hepher, 1988; Steffens, 1989). A deficiência de vitamina A é a segunda forma mais comum de má nutrição. Por consequiência, é importante determinar as exigências nutricionais desta vitamina para as diferentes espécies animais utilizadas em produção comercial, especialmente a partir da quantificação dos depósitos hepáticos (Hole e Taylor, 1996).

\subsection{Fontes de vitamina $\mathrm{A}$}

Algumas vitaminas, inclusive a vitamina $\mathrm{A}$, não podem ser sintetizadas pelos animais superiores, e devem ser suplementadas como parte da dieta animal (Latscha, 1991). Muitos vegetais contêm compostos isoprenóides conhecidos como carotenóides, que podem ser convertidos em vitamina A pela maioria dos animais através da ação de enzimas específicas (Lehninger, 1991; Blomhoff, 1994). Carotenóides, precursores da vitamina $\mathrm{A}$, são pigmentos lipossolúveis que também não podem ser sintetizados pelos peixes; agem sobre o comportamento sexual e atividade do sistema imunológico (Fracalossi, 1998). 
Segundo Blomhoff (1994) a absorção de carotenóides ocorre por difusão passiva, e em humanos foi registrado que a taxa de absorção destes pigmentos varia entre $5 \%$ e 50\%. A eficiência de absorção parece ser dependente da quantidade de gordura dietética. Matsuyama e Matsuno (1988) afirmam que $\beta$-caroteno é o carotenóide com a maior porcentagem de utilização pela tilápia, uma taxa de bioconversão da ordem de $15,9 \%$.

Carotenóides podem apresentar outra função além de servir como fonte de vitamina A. Amar et al. (2001) testaram a influência de vários carotenóides sintéticos no mecanismo de bio-defesa em truta arco-íris Oncorhynchus mykiss, e concluíram que os carotenóides não influenciaram as respostas imunes não específicas, tal como imunoglobulina total plasmática. Entretanto, na presença das vitaminas A, C e E, os carotenóides tiveram grande influência nos mecanismos de bio-defesa da truta arco-íris.

De forma geral, dietas para peixes onívoros e herbívoros contêm maior quantidade de proteína vegetal que animal, sendo esta última uma fonte natural de vitaminas lipossolúveis. Farinhas e óleos de pescado usados como fonte de proteína animal em rações para peixes carnívoros, podem ser considerados como fontes de vitamina A e D, sendo que alguns destes produtos concentram até 50.000 UI de vitamina A e 45.000 UI de vitamina D por grama de fígado (Ferreira, 1987).

O óleo de peixe é fonte natural de vitamina A, mas diferenças extremas em níveis da mesma vitamina são observadas em várias espécies. Peixes selvagens podem apresentar algumas diferenças na composição de vitaminas hidrossolúveis durante a migração, maturação ou quando privados de alimento. Entretanto, estas diferenças não são tão extremas quanto para vitaminas lipossolúveis (Lall \& Parazo, 1995). Assim sendo, peixes mantidos em sistemas intensivos de criação são completamente dependentes de suplementação dietética de vitaminas, e se estas não forem incluídas na dieta, sinais de deficiência de vitaminas A, D, E, e K certamente aparecerão (Hepher, 1988). 


\subsection{Deficiência de vitamina A e hipervitaminose A}

A deficiência da vitamina A causa danos no epitélio, tecidos ósseos e conjuntivos (NRC, 1993; Lehninger, 1991). Em truta arco-íris a deficiência de vitamina A causa diminuição na migração de leucócitos, tendo um potencial limitante como agente imunoestimulatório na dieta desta espécie (Thompson et al., 1995). Harikumar et al. (1996) demonstraram que dietas deficientes em vitamina A resultaram em crescimento reduzido, perda da massa muscular, alta taxa de mortalidade, perda da pigmentação, entre outros efeitos de diferentes parâmetros patológicos em Heteropneustes fossilis. Goswami e Dutta (1988) também observaram que H. fossilis alimentados com dietas isentas de vitamina A apresentam anemia, diminuição no número de hemoglobina e eritrócitos, leucócitos e trombócitos, inibição da síntese de eritroblastos junto com a redução do tamanho do citoplasma e do núcleo dos diferentes corpúsculos celulares.

Peixes alimentados com dietas isentas de vitamina A gradualmente perdem o composto, primeiro dos armazenamentos do fígado e por último dos olhos. Alguns meses após começar a ingerir dietas sem vitamina A, juvenis de Carassius auratus apresentaram sinais de deficiência e passaram a mostrar maior susceptibilidade a infecções bacterianas (Graham e Jones, 1969). Neste mesmo trabalho os autores observaram evidência de avitaminose no fígado, glândulas intestinais e particularmente na pele, onde foram observadas camadas queratinizadas.

De modo oposto, a hipervitaminose A (122 e $938 \mathrm{mg}$ retinol $\mathrm{kg}^{-1}$ dieta) em larvas de salmão do Atlântico causou redução nos depósitos de gordura, no tamanho do fígado e no crescimento. Efeitos tóxicos da vitamina A - taxa de mortalidade aumentada, crescimento anormal da coluna vertebral e crescimento reduzido - foram observados com $938 \mathrm{mg}$ retinol $\mathrm{kg}^{-1}$ de dieta (Ornsrud et al, 2002). Larvas de linguado japonês alimentadas com Artemia enriquecida com grandes quantidades de vitamina A (100.000 UI de retinol, retinil palmitato e retinil acetato ou $100.000 \mu \mathrm{g}$ de ácido alltrans-retinóico $10 \mathrm{~L}^{-1}$ de suspensão) tiveram vértebras comprimidas e redução na taxa de crescimento. Os autores concluíram que esta quantidade de vitamina A foi tóxica para os 
peixes provavelmente devida à grande quantidade de ácido retinóico (Takeuchi et al., 1995; Takeuchi et al., 1998).

\subsection{Exigências nutricionais de vitamina A}

A composição de uma dieta animal deve considerar todas as exigências nutricionais da espécie produzida: vitaminas, energia, proteína, lipídios e minerais (Latscha, 1991). Nas determinações em exigências nutricionais para peixes (NRC, 1993), maior ênfase tem sido dada ao estudo de vitaminas hidrossolúveis, pois estas estão diretamente relacionadas a vetores de doenças ou outros estressantes e não são facilmente armazenadas pelos animais (Halver, 1985). Já as vitaminas lipossolúveis podem ser facilmente armazenadas no corpo animal junto com as reservas de gorduras; sendo assim é mais difícil observar a deficiência das mesmas.

Os níveis exigidos são definidos como a concentração mínima que resultam na maior taxa de crescimento, na maior concentração da vitamina testada no fígado, e ausência de anormalidades com respeito à constituição sangüínea e histológica. Às vezes outros critérios bioquímicos são usados na avaliação das exigências em vitaminas, normalmente como um conjunto dos parâmetros de crescimento (Hepher, 1988).

Quantidades inadequadas de vitaminas nas dietas podem resultar em doenças relacionadas à nutrição, crescimento reduzido ou aumento da susceptibilidade a infecções (Hepher, 1988; NRC, 1993; de Silva \& Anderson, 1995). Para carnívoros de águas frias, Halver (1985) recomenda o nível de 2.000 a 3.000 UI de vitamina $\mathrm{A} \mathrm{kg}^{-1}$ de dieta, com um nível aceitável de até 4.000 UI de vitamina $\mathrm{A} \mathrm{kg}^{-1}$ de dieta. O NRC (1993) recomenda os seguintes níveis de inclusão de vitamina $\mathrm{A}$ em UI kg${ }^{-1}$ de dieta: 2.500 para truta arco-íris; 1.000 a 2.000 para bagre do canal; e 4.000 a 20.000 para carpa comum. Hepher (1988) recomenda níveis de vitamina A de $2.500 \mathrm{UI} \mathrm{kg}^{-1}$ de dieta para salmão; 2.000 UI a $15.000 \mathrm{UI} \mathrm{kg}^{-1}$ de dieta para truta; 1.000 a $20.000 \mathrm{UI} \mathrm{kg}^{-1}$ de dieta para carpa comum; e $5.500 \mathrm{UI} \mathrm{kg}^{-1}$ de dieta para bagre do canal.

Fracalossi (1998) relata que os efeitos da vitamina A em peixes não foram muito estudados. De fato, trabalhos atuais de revisão bibliográfica relatam resultados de 
experimentos realizados nas décadas de 60 e 70 contemplando estudos sobre a ausência ou o excesso (acima de $1000 \mathrm{UI} \mathrm{kg}^{-1}$ de ração) de vitamina $\mathrm{A}$ em dietas para várias espécies de peixes (Halver, 1985; Hepher, 1988; Steffens, 1989; NRC, 1993; de Silva e Anderson, 1995).

As exigências nutricionais para a maioria das vitaminas foram estabelecidas para salmonídeos, carpas e bagres (Lovell, 1998), enquanto somente algumas exigências, como vitaminas $\mathrm{E}, \mathrm{C}$ e $\mathrm{B}_{12}$ são conhecidas para tilápia do Nilo (NRC,1993). Uma adição a este rol de conhecimentos aparece na forma do trabalho desenvolvido por Saleh et al. (1995), que determinaram, a partir do estudo de níveis de inclusão de vitamina $\mathrm{A}$ em dietas práticas, contendo farinha de peixe e de vísceras, que a exigência nutricional em vitamina A para a tilápia do Nilo é de $5.000 \mathrm{UI} \mathrm{kg}^{-1}$ de dieta. 


\section{MATERIAL E MÉTODOS}

Os ensaios foram conduzidos no Laboratório de Nutrição de Peixes do Setor de Piscicultura do Departamento de Zootecnia da Escola Superior de Agricultura "Luiz de Queiroz” da Universidade de São Paulo, em Piracicaba, São Paulo, Brasil (22 42’30” S; $47^{\circ} 38^{\prime} 00^{\prime \prime} \mathrm{W}$; altitude $\left.546 \mathrm{~m}\right)$. Os peixes foram alojados em aquários de polipropileno com capacidade para $100 \mathrm{~L}$ (1 alevino $10 \mathrm{~L}^{-1}$ água) com troca parcial de água num sistema fechado de recirculação e aeração forçada por soprador e pedras difusoras, com controle e manutenção da temperatura da água $\left(26,0 \pm 1,0^{\circ} \mathrm{C}\right)$ através de um turbo aquecedor. Os ensaios foram conduzidos em delineamento experimental inteiramente casualizado em arranjo fatorial $2 \times 10(\mathrm{n}=4)$. As variáveis de qualidade da água $\mathrm{pH}$, oxigênio dissolvido (OD) e temperatura foram monitoradas diariamente como prática de rotina do laboratório, através de um "kit" de análises de água HACH, Mod. FF-42 Aqüicultura.

Foram utilizadas: uma população monosexo de alevinos de tilápia do Nilo (R), produzida pelo processo de reversão sexual (peso inicial 13,76 $\pm 1,21 \mathrm{~g}$ ) adquirida de um produtor comercial; e uma população natural (NR) (peso inicial 9,83 $\pm 2,30 \mathrm{~g}$ ), proveniente do setor de Piscicultura da ESALQ. Por quinze dias anteriormente ao início da alimentação com as dietas experimentais, os peixes foram aclimatizados nos aquários e alimentados com uma dieta semi-purificada isenta de vitamina A, visando simular ou induzir a deficiência do nutriente investigado (NRC, 1993).

Os peixes de ambas populações foram então alimentados durante setenta e cinco dias com rações semipurificadas contendo diferentes níveis de inclusão de vitamina A: $0,600,1.200,1.800,2.400,3.000,3.600,4.200,4.800$ e 5.400 UI de 
vitamina $\mathrm{kg}^{-1}$ da dieta (Tabela 1). Foi utilizada como fonte de vitamina A o retinil palmitato, 30\% vitamina A (Rovimix A 500 Roche $^{\circledR}$ ).

Tabela 1. Composição das dietas experimentais.

\begin{tabular}{|c|c|}
\hline Ingredientes & Quantidades \\
\hline Albumina & 32,10 \\
\hline Gelatina & 7,70 \\
\hline Amido & 44,13 \\
\hline Óleo de Soja & 6,0 \\
\hline$\alpha$-Celulose & 6,0 \\
\hline Fosfato Bicálcico & 3,0 \\
\hline Pré-mistura de vitaminas e minerais ${ }^{1}$ & 0,50 \\
\hline Vitamina $C^{2}$ & 0,05 \\
\hline Cloreto de Sódio & 0,50 \\
\hline $\mathrm{BHT}^{3}$ & 0,02 \\
\hline \multicolumn{2}{|l|}{ Composição em nutrientes } \\
\hline Umidade (\%) & 7,91 \\
\hline Energia Bruta $\left(\mathrm{kcal} \mathrm{kg}^{-1}\right)$ & 4791 \\
\hline Proteína Bruta (\%) & 34,70 \\
\hline Extrato Etéreo (\%) & 2,65 \\
\hline Fibra Bruta (\%) & 3,83 \\
\hline Matéria Mineral (\%) & 4,79 \\
\hline \multicolumn{2}{|c|}{${ }^{1}$ Níveis de garantia por quilograma da mistura vitamínico e mineral (Supremais) por kg de produto: vit. $\mathrm{D}_{3} 200.000$} \\
\hline \multicolumn{2}{|c|}{ UI; vit E $12.000 \mathrm{mg}$; vit. $K_{3} 2.400 \mathrm{mg}$; vit $B_{1} 4.800 \mathrm{mg}$; vit $B_{2} 4.800 \mathrm{mg}$; vit $B_{6} 4000 \mathrm{mg}$; vit $B_{12} 4.800 \mathrm{mg}$; ác. fólico } \\
\hline \multirow{2}{*}{\multicolumn{2}{|c|}{$\begin{array}{l}1.200 \mathrm{mg} \text {; pantotenato de cálcio } 1.200 \mathrm{mg} \text {; vit C } 48.000 \text { mg; biotina } 48 \text { mg; niacina } 24.000 \text { mg; Fe } 10.000 \mathrm{mg} \text {; Cu } 600 \\
\mathrm{mg} \text {; Mn } 4.000 \mathrm{mg} \text {; Zn } 6.000 \mathrm{mg} \text {; I } 20 \text { mg; Co } 2 \text { mg; Se } 20 \mathrm{mg} \text {. }\end{array}$}} \\
\hline & \\
\hline \multicolumn{2}{|c|}{$\begin{array}{l}\left.{ }^{2} \text { Vit. C (Lutavit C- Aquastab BASF }{ }^{\circledR}\right) \text {; sal cálcica 2-monofosfato de ácido ascórbico com 42\% de princípio ativo. } \\
{ }^{3} \text { BHT= Butil hidroxi tolueno. }\end{array}$} \\
\hline
\end{tabular}

Os peixes foram alimentados ad libitum em duas refeições diárias $(06 \mathrm{~h} 00 \mathrm{~m}$ e $18 \mathrm{~h} 00 \mathrm{~m})$, sete dias por semana. Durante e ao final do experimento foram feitas observações visuais dos animais para caracterização dos sinais de deficiência. Foram analisados cinco índices de desempenho zootécnicos: peso final, ganho de peso [(peso final) - (peso inicial)], consumo de ração, conversão alimentar [(consumo de ração) $\div$ 
(ganho de peso) $]$ e sobrevivência $[100 \mathrm{x}$ (número de animais final) $\div$ (número de animais inicial)].

As coletas de dados biométricos da população foram realizadas ao início e ao final do período experimental. Para a pesagem dos animais no início do experimento foi utilizado o anestésico benzocaína para minimizar o estresse. Ao final do experimento os animais foram sacrificados em água com gelo fundente e em seguida submetidos à biometria.

Ao final do período experimental, os fígados dos peixes foram retirados através de laparotomia abdominal esquerda e armazenados imediatamente em nitrogênio líquido Para a análise dos lipídios hepáticos e quantificação da vitamina A foi utilizada Cromatografia Líquida de Alta Eficiência (Landen \& Eitenmiller, 1979).

Os dados foram submetidos a análise de variância usando-se PROC GLM do aplicativo SAS (SAS, 2001). O desdobramento da análise de variância foi feito através da análise de regressão (PROC GLM), determinando-se os efeitos lineares e quadráticos dos tratamentos sobre as variáveis peso final (PF), ganho de peso (GP), conversão alimentar (CA) e sobrevivência (S). 


\section{RESULTADOS E DISCUSSÃO}

\subsection{Sinais de deficiência}

No presente trabalho foram observados os mesmos sinais clínicos de deficiência para os animais dos grupos revertidos (R) e do não-revertidos (NR) com deficiência nutricional de vitamina A. Foram visualmente observados sinais de deficiência de vitamina A no grupo de animais NR. Nos grupos alimentados com dieta isenta de vitamina A foi observado que todos os animais tinham baço necrosado, granulomatosos e de tamanho aumentado. Fígados e todo o trato digestivo destes animais estavam visualmente amorfos.

A autópsia de duas fêmeas moribundas do tratamento 0 do grupo NR realizada na segunda quinzena de experimento revelou fígados de coloração normal mas vesícula biliar de cor escura, sinal clínico característico de estresse (Halver, 1989; Steffens, 1989; Tacon, 1992). No decorrer e ao final do experimento foi ainda registrada a ocorrência dos seguintes sinais clínicos relacionados à deficiência nutricional de vitamina A: hemorragia na nadadeira lateral, catarata, exoftalmia, ascite, dilaceração renal, empalidecimento do fígado, granulomas e necrose hepática e no baço. A incidência de sinais clínicos de deficiência nutricional de vitamina diminuiu à medida que o nível de suplementação dietética do nutriente aumentou (Tabela 2). 
Tabela 2. Incidência de sinais clínicos de deficiência de vitamina A observados.

\begin{tabular}{|c|c|c|c|c|c|c|c|c|c|c|c|c|c|c|c|c|c|c|c|c|}
\hline \multirow{3}{*}{$\begin{array}{l}\text { Dieta (mg vit } \mathrm{A} \mathrm{kg}^{-1} \text { ) } \\
\text { Sinais clínicos durante } \\
\text { experimento }\end{array}$} & \multicolumn{20}{|c|}{ Incidência de sinais clínicos de deficiência } \\
\hline & \multicolumn{2}{|c|}{0} & \multicolumn{2}{|c|}{600} & \multicolumn{2}{|c|}{1200} & \multicolumn{2}{|c|}{1800} & \multicolumn{2}{|c|}{2400} & \multicolumn{2}{|c|}{3000} & \multicolumn{2}{|c|}{3600} & \multicolumn{2}{|c|}{4200} & \multicolumn{2}{|c|}{4800} & \multicolumn{2}{|c|}{5400} \\
\hline & $\mathrm{R}$ & NR & $\mathrm{R}$ & NR & $\mathrm{R}$ & NR & $\mathrm{R}$ & NR & $\mathrm{R}$ & NR & $\mathrm{R}$ & NR & $\mathrm{R}$ & NR & $\mathrm{R}$ & NR & $\mathrm{R}$ & NR & $\mathrm{R}$ & NR \\
\hline Fígado pálido & & 1 & & 1 & & & & & 4 & & 3 & & & & & & & & & 1 \\
\hline Pele sem escama & & 1 & & & & 1 & & & & & & & & & & 1 & & & & \\
\hline Catarata & & & 2 & & & & & 1 & & 1 & & 1 & & & & & & & & \\
\hline $\begin{array}{l}\text { Hemorragia Nadadeira } \\
\text { Lateral }\end{array}$ & & & & & & & & & & & & & & 1 & & & & & & \\
\hline Exoftalmia & & & & & & & & & & & & & & & 1 & & & & & \\
\hline $\begin{array}{l}\text { Sinais clínicos pós } \\
\text { experimento }\end{array}$ & & & & & & & & & & & & & & & & & & & & \\
\hline Ascite & & & & & & 1 & & & & & & 1 & & & & & & & & \\
\hline $\begin{array}{l}\text { Baço necrosado com } \\
\text { granulomas }\end{array}$ & 38 & 38 & 20 & 38 & 16 & 27 & 13 & 11 & 11 & 3 & 5 & 1 & & 1 & & 1 & & & & \\
\hline $\begin{array}{l}\text { Fígado amorfo com } \\
\text { granulomas }\end{array}$ & 30 & 38 & 30 & 30 & 16 & 38 & & & & & & & & 1 & & 1 & & 1 & & \\
\hline Rim amorfo & 20 & 20 & 20 & 30 & 30 & & & & & & & & & & & & & & & \\
\hline
\end{tabular}

Segundo Saleh et al. (1995), sinais de deficiência de vitamina A em O. niloticus incluem: comportamento natatório anormal; cegueira e hemorragias e protrusões nos olhos; anemia, hemorragia na base das nadadeiras e na pele. Em estado adiantado de deficiência o autor observou ainda: despigmentação generalizada e edemas no abdômen, às vezes associado a ascite; redução da secreção e aparecimento de tecido seco e duro na mucosa. As lesões post-mortem observadas apareceram em forma de fluidos na cavidade abdominal, guelras fundidas e hemorragias nos rins, este último sinal encontrado no presente trabalho em peixes que receberam menos que $1.200 \mathrm{UI}$ vitamina $\mathrm{A} \mathrm{kg}^{-1}$ de dieta.

Taveekijakarn et al. (1994) também observaram sintomas semelhantes aos descritos acima, como resultado da deficiência de vitamina A em Oncorhynchus masou, após 15 semanas de experimento. Lesões hepáticas foram os sinais mais evidentes em animais com deficiência. Segundo os autores, estas alterações hepáticas podem ter sido causadas pela redução da fibronectina sob condições de deficiência de vitamina A. As lesões observadas a 15 e 22 semanas de tratamento foram as mesmas, mas a severidade dos sinais aumentou com o tempo.

Sinais clínicos semelhantes aos observados no presente trabalho foram relatados por Harikumar et al. (1996) para o bagre Heteropneustes fossilis, que 
apresentou parada do crescimento, perda de peso corporal e massa muscular, despigmentação da pele e alteração do hematócrito quando alimentado com dietas isentas de vitamina A. Os autores notaram que a esfoliação da pele e músculo induzida pelo estresse dietético também causou liberação de proteinases (catepsina $\mathrm{B}$ e $\mathrm{H}$ ) nestes tecidos.

No presente trabalho foram observados alguns animais com catarata. Poston et al. (1977) observaram: (a) degeneração da retina em alevinos de truta arco-íris alimentados com dietas isentas de vitamina A por 11 semanas; e (b) despigmentação dérmica em lotes de truta do riacho Salvelinus fontinalis alimentados com dietas isentas de vitamina $\mathrm{A}$ ou com altos níveis de $\beta$-caroteno por 8 a 10 semanas. Exoftalmia foi observada nestes mesmos lotes após 6 semanas de experimento.

Ainda segundo Poston đ al. (1977), pós-larvas de truta alimentadas com dieta semipurificada deficiente em vitamina A desde a primeira alimentação, cresceram lentamente, desenvolveram edemas, lesões na córnea e degeneração na retina, mas não cataratas. Entretanto, trutas mais velhas, alimentadas com a mesma dieta, mas previamente alimentadas com dieta que continha vitamina A, não apresentaram lesões oculares ou outros sinais de deficiência. O presente trabalho foi iniciado com alevinos avançados, o que pode explicar a baixa incidência de sinais clínicos oculares de deficiência em vitamina A.

\subsection{Desempenho}

Os resultados de desempenho zootécnico para os índices ganho de peso (GP), conversão alimentar (CA), sobrevivência (S) e consumo de ração (CR) estão apresentados na Tabela 3. O desdobramento da análise de variância foi feito através de análise de regressão para níveis nas variáveis onde foram detectadas diferenças significativas. Para as variáveis PF e CA foi encontrado um efeito linear $(\mathrm{P}<0,01)$, indicando que para cada aumento de concentração de vitamina A (600 UI kg ${ }^{-1}$ ), aumenta-se o PF em 0,8 g e que para cada aumento na concentração de vitamina A há uma diminuição na conversão alimentar de 0,05 . Para a variável GP não foi encontrado 
efeito significativo $(\mathrm{P}>0,05)$. Este resultado é provavelmente devido à diferença no peso inicial dos animais utilizados. As equações definidas fora: (a) para as variáveis de efeito linear $y=\beta_{0}+\beta_{1} x_{1}$; e (b) para as variáveis de efeito quadrático: $y=\beta_{0}+\beta_{1} x_{1}+\beta_{2} x_{1}^{2}$ (Figuras 1 e 2). Saleh et al. (1995), observaram o maior ganho de peso corpóreo (23,9 g), maior taxa de consumo de ração $(60,2$ g) e melhor taxa de conversão alimentar $(2,5)$ nos grupos que receberam a dieta contendo 5.000 UI vitamina A. $\mathrm{kg}^{-1}$.

Tabela 3. Médias das variáveis de desempenho analisadas para os tratamentos.

\begin{tabular}{|c|c|c|c|c|c|}
\hline \multicolumn{6}{|c|}{ Parâmetros de Desempenho } \\
\hline Grupo & $\mathrm{PI}(\mathrm{g})$ & $P F(g)$ & GP $(g)$ & $\mathrm{CR}(\mathrm{g})$ & $\mathrm{CA}$ \\
\hline $\mathrm{R}$ & 13,76 & 43,70 & 29,94 & 33,82 & 1,12 \\
\hline NR & 9,83 & 27,03 & 17,22 & 25,45 & 1,49 \\
\hline \multicolumn{6}{|l|}{ Tratamento } \\
\hline $0 \mathrm{UI} / \mathrm{kg}$ & 11,14 & 31,61 & 20,46 & 32,46 & 1,58 \\
\hline $600 \mathrm{UI} / \mathrm{kg}$ & 10,64 & 30,09 & 19,45 & 29,62 & 1,53 \\
\hline $1200 \mathrm{UI} / \mathrm{kg}$ & 11,94 & 33,29 & 21,35 & 28,83 & 1,38 \\
\hline $1800 \mathrm{UI} / \mathrm{kg}$ & 11,70 & 32,84 & 21,14 & 26,04 & 1,28 \\
\hline $2400 \mathrm{UI} / \mathrm{kg}$ & 12,93 & 36,72 & 23,79 & 28,16 & 1,20 \\
\hline $3000 \mathrm{UI} / \mathrm{kg}$ & 12,73 & 37,24 & 24,51 & 29,10 & 1,20 \\
\hline $3600 \mathrm{UI} / \mathrm{kg}$ & 12,56 & 38,58 & 26,02 & 30,85 & 1,23 \\
\hline $4200 \mathrm{UI} / \mathrm{kg}$ & 10,97 & 37,02 & 26,05 & 29,90 & 1,17 \\
\hline $4800 \mathrm{Ul} / \mathrm{kg}$ & 11,74 & 37,49 & 25,75 & 29,34 & 1,16 \\
\hline $5400 \mathrm{UI} / \mathrm{kg}$ & 11,55 & 38,81 & 27,26 & 32,04 & 1,20 \\
\hline
\end{tabular}

$\mathrm{PI}=$ peso inicial $; \mathrm{PF}=$ peso final $\mathrm{GP}=$ ganho de peso $\mathrm{CR}=$ consumo de ração $\mathrm{CA}=$ conversão alimentar 


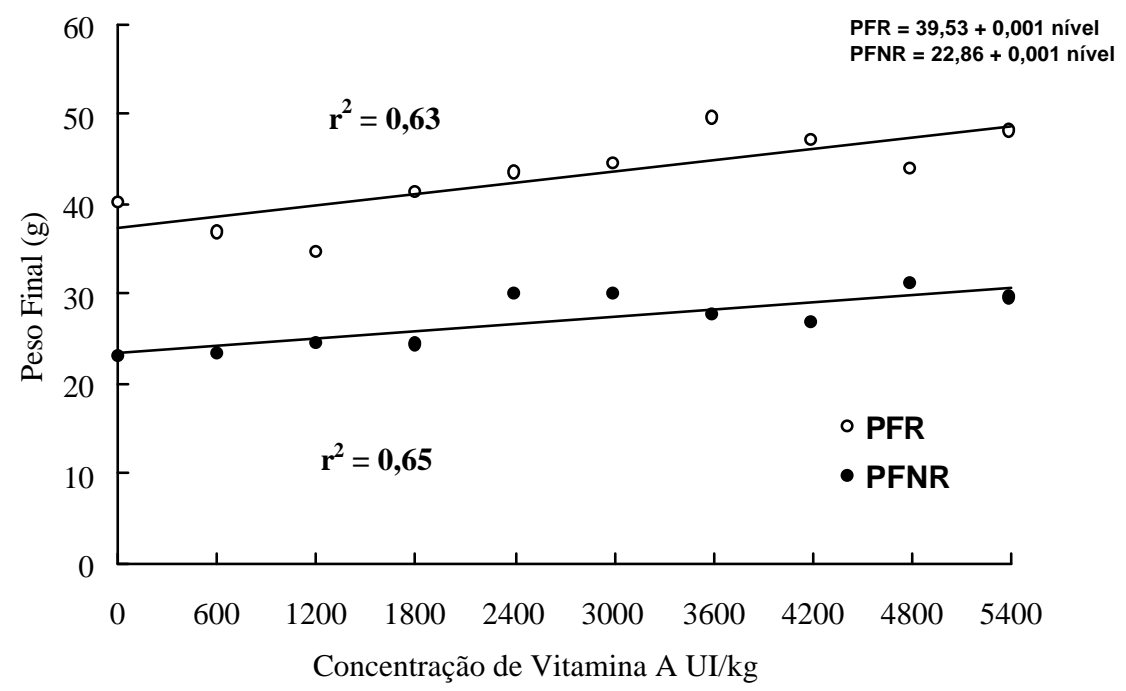

Figura 1 - Peso final dos animais em resposta aos diferentes níveis de inclusão de vitamina A.

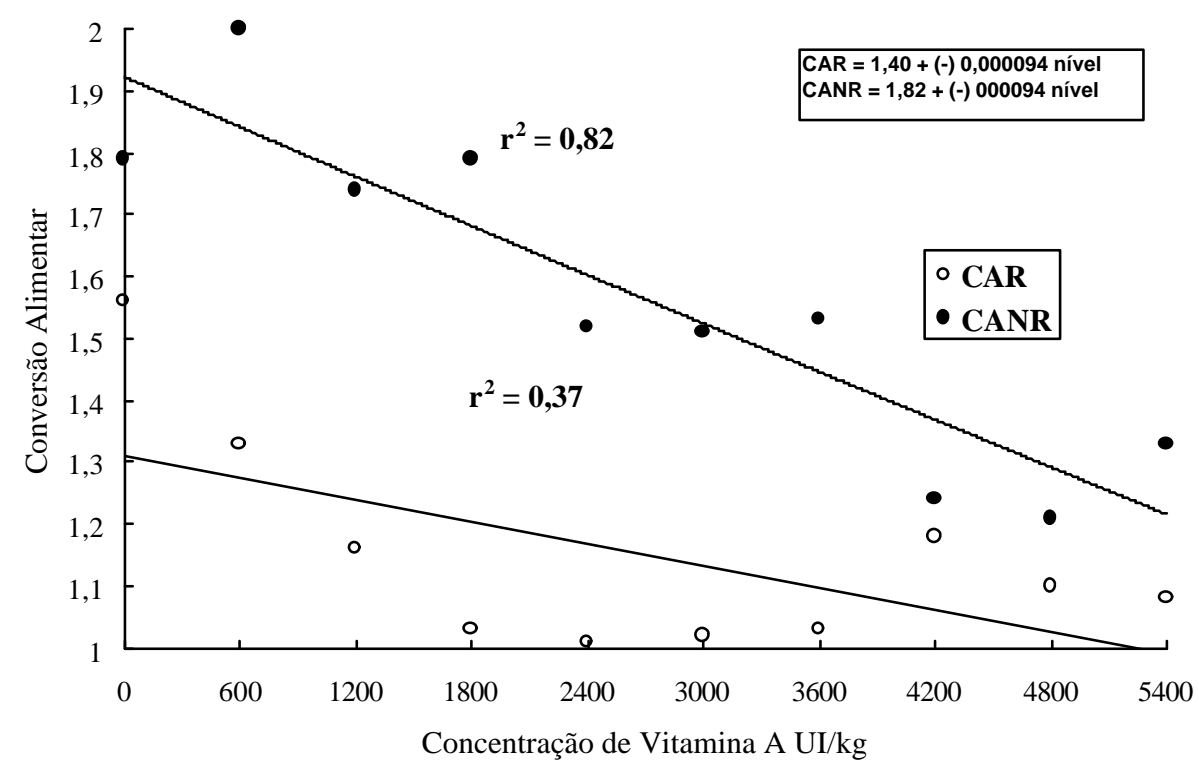

Figura 2 - Conversão alimentar dos animais em resposta aos diferentes níveis de inclusão de vitamina A. 
A taxa de sobrevivência apresentou efeito quadrático $(\mathrm{P}<0,001)$. Houve um ligeiro aumento no número índice de sobrevivência à medida que a taxa de inclusão de vitamina aumentou (Figura 3). Estudos sobre a relação entre dieta isenta de vitamina A e taxa de sobrevivência em lotes de peixes de várias espécies diferentes foram realizados por vários autores que observaram diferentes respostas, às vezes paradoxais.

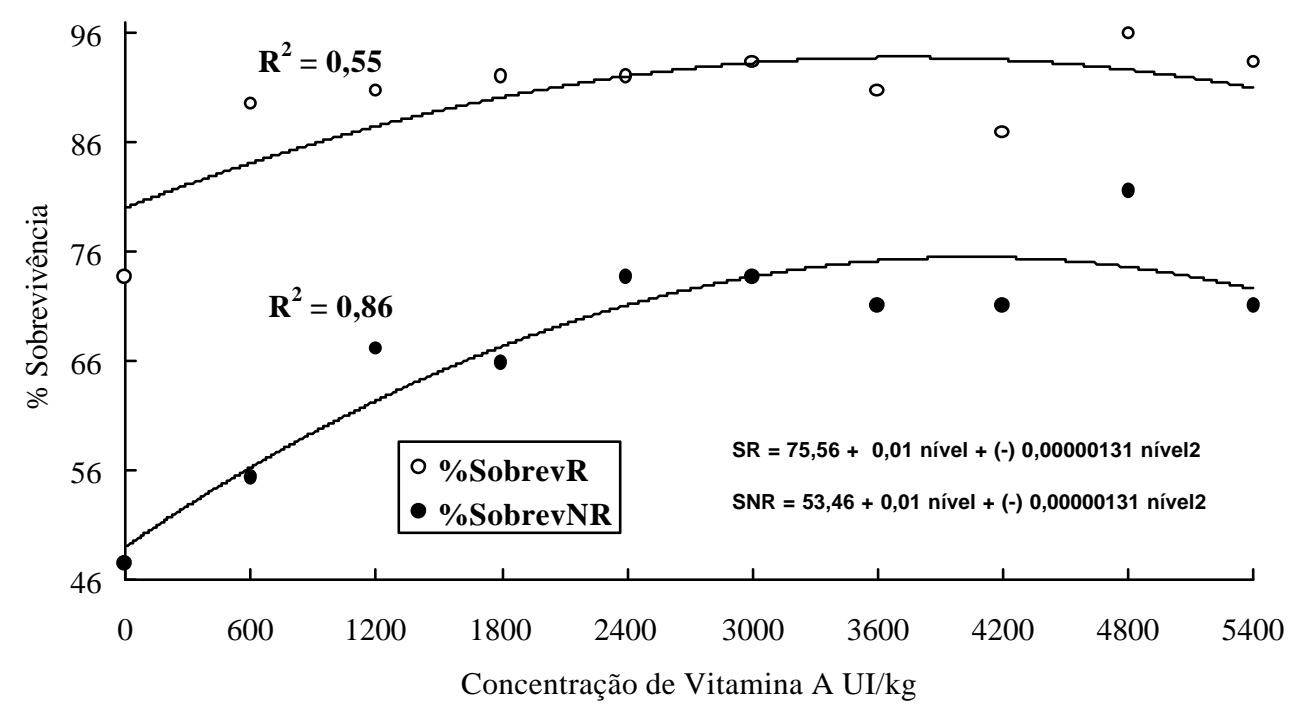

Figura 3 - Taxa de Sobrevivência em resposta aos diferentes níveis de inclusão de vitamina A.

Saleh et al. (1995) relataram que grupos de tilápia do Nilo que receberam ração adicionada de 5.000 e 10.000 UI de vitamina $\mathrm{A} \mathrm{kg}^{-1}$ apresentaram taxas de sobrevivência de 93\%. Entretanto, grupos alimentados com dietas contendo 40.000 UI vitamina $\mathrm{A} \mathrm{kg}^{-1}$ apresentaram taxas de sobrevivência de $77 \%$. Mortalidade em lotes de salmão cereja alimentados com dietas isentas de vitamina A teve início após 15 dias de experimento (Taveekijakarn et al., 1994). Em experimento com salmão do Atlântico, a mortalidade durante as últimas 8 semanas foi de $0,9 \%$. Esta taxa foi influenciada pelo nível de vitamina $\mathrm{A}$ adicionada à dieta $\left(72.500,77.500\right.$ e $\left.122.500 \mathrm{UI} \mathrm{kg}^{-1}\right)$ e pela interação entre as vitaminas A e $\mathrm{K}$, testados no mesmo experimento (adição de $300 \mathrm{mg}$ de bissulfato 
sódico de menadiona - MSB $\mathrm{kg}^{-1}$ ) ou equivalentes de vitamina $\mathrm{K}_{1}$ (Grisdale -Helland et al., 1991).

Ao contrário do que foi observado neste e em outros trabalhos, a sobrevivência do linguado japonês alimentado com microcrustáceos (Artemia salina) enriquecidas com vitamina A (0 - $100 \mathrm{mg})$ não foi afetada pelos tratamentos (Dedi et al., 1995). A taxa de mortalidade de alevinos de truta arco-íris também não foi significativamente influenciada pela alimentação com dietas isentas de vitamina $\mathrm{A}$ ou com dietas contendo 10.000 UI de retinil palmitato $\mathrm{kg}^{-1}$ durante um período máximo de 20 semanas (Poston et al., 1977). Testando a interação entre a temperatura da água, a vitamina A e carotenos, Poston et al. (1977) observaram ainda que alevinos de truta de riacho alimentados com dieta contendo 10.000 UI vitamina $\mathrm{A} \mathrm{kg}^{-1}$ apresentam a taxa de sobrevivência significativamente maior em temperaturas médias de $9{ }^{\circ} \mathrm{C}$.

Os lotes $\mathrm{R}$ apresentaram melhor desempenho - maiores taxas de peso final, ganho de peso, consumo de ração e melhor taxa de conversão alimentar - quando comparados com os lotes de animais heterosexo, independente do nível de inclusão de vitamina A na dieta (Figuras 1 e 2). Em trabalho analisando comportamento alimentar em aquários contendo machos e fêmeas ou somente machos, Toguyeni et al. (1997), também observaram que os grupos monosexo tiveram maior índice de crescimento, com diferenças significativas entre machos e fêmeas.

No presente trabalho foi observado desde o início problemas com territorialidade durante a alimentação. Este problema foi mais evidente nos grupos monosexo. O mesmo tipo de problema foi observado por Toguyeni et al. (1997), não só em grupos monosexo, mas também nos grupos heterosexo. Problemas com a alimentação e hierarquia também foram observados por McCarthy et al. (1999) para Tilapia rendalli. Estes resultados corroboram observações de outros autores que sugerem que a causa dos grupos heterosexo terem pior eficiência alimentar é atividade social mais intensa existente nestes grupos, demonstrando que interações entre machos e fêmeas causam efeito negativo no crescimento. 


\subsection{Quantidade de retinol hepático}

Análises de cromatografia líquida de alta eficiência (CLAE ou HPLC) não detectaram vitamina A no fígado dos animais referentes aos tratamentos de 0 à 4.800 UI de retinol $\mathrm{kg}^{-1}$ de ração. Somente no fígado dos animais que receberam o mais alto nível de inclusão de retinol, $5400 \mathrm{UI} \mathrm{kg}^{-1}$ de ração, foi encontrada a quantia de $136 \pm 10 \mu \mathrm{g}$ de vitamina A $100 \mathrm{~g}^{-1}$ de fígado. Isto significa que somente neste nível a vitamina A encontrada no animal estava excedendo a necessidade metabólica e, assim sendo, foi armazenada no fígado.

Camargo et al. (1975) determinaram as concentrações de retinol e outros derivados de vitamina A em seis espécies de peixes capturados no rio Moji-Guaçu, situado no Estado de São Paulo. A quantidade de retinol encontrada no curimbatá Prochilodus scrofa foi $3,32 \mathrm{mg} \mathrm{g}^{-1}$; no dourado Salminus maxillosus 7,62 $\mathrm{mg} \mathrm{g}^{-1}$; na piapara Leporinus piapara 4,30 $\mathrm{mg} \mathrm{g}^{-1}$; na mandiúva Pimelodus clarias 2,85 $\mathrm{mg} \mathrm{g}^{-1}$; na piava Leporinus copelandi 3,40 $\mathrm{mg}^{1}$. Hole e Taylor (1996) encontraram a quantia de $0,047 \mathrm{mg} \mathrm{g}^{-1}$ de retinol no óleo do fígado do cação "dogfish” Squalus acanthias.

Embora abaixo das médias encontradas para peixes capturados na natureza, que têm à disposição farto suprimento de vitamina A no alimento natural, a quantidade de retinol hepático encontrada neste trabalho encontra-se dentro do previsível para as condições experimentais. De fato, Saleh et al. (1995) observaram que os melhores índices de desempenho de tilápias são conseguidos com níveis de suplementação iguais ou superiores a $5.000 \mathrm{UI} \mathrm{kg}^{-1}$ de dieta. 


\section{CONCLUSÕES}

Embora os dados de desempenho mostrem que o nível de 4.800 UI de retinol $\mathrm{kg}^{-1}$ de ração seja o suficiente para um bom desenvolvimento de juvenis de tilápia, a análise cromatográfica garante que a partir do nível de 5.400 UI de retinol $\mathrm{kg}^{-1}$ de ração o animal terá um desenvolvimento otimizado. 


\section{REFERÊNCIAS BIBLIOGRÁFICAS}

ADESULU, E.A.; MUSTAPHA, A.K. Use of housefly maggots as a fishmeal replacer in tilapia culture: A recent vogue in Nigeria. In: INTERNATIONAL SYMPOSIUM OF TILAPIA AQUACULTURE 5., Rio de Janeiro, 2000. Anais. Rio de Janeiro: Panorama da Aqüicultura, 2000. v 1, p.138-143.

AMAR, E.C.; KIRON, V.; SATOH, S. et al. Influence of various dietary synthetic carotenoids on bio-defense mechanisms in rainbow trout, Oncorhynchus mykiss (Walbaum). Aquaculture Research, n.32, suppl. 1. p.162-173, 2001.

ASSOCIATION OF VITAMIN CHEMISTS. Methods of vitamin assay. 3.ed. New York: Interscience Publ, 1966. p.301

BLOMHOFF, R. Transport and metabolism of vitamin A. Nutrition Reviews, v.2, n.52, p.S13-S23, 1994.

CAMARGO, L.A.A.; YASHUDA, Y.;. SAAD, W.A. Vitamina A em óleo de fígado de peixes brasileiros de água doce. Archivos Latinoamericanos de Nutrición, v.25, n.3, p.273-281, 1975.

CASTANGOLLI, N. Estado da arte da tilapicultura no Brasil. In: SIMPÓSIO BRASILEIRO DE AQUICULTURA, 12., Goiânia, 2002. Anais. Goiânia: UFG, 2002. p.116.

COMBS Jr., G.F. The vitamins, fundamental aspects in nutrition and health London: Academic Press, 1992. 528 p.

DAVIS, K.B.; SIMCO, W.A. et al. Effect of reduction of supplementary dietary vitamins on the stress response of channel catfish Ictalurus punctatus. Journal of The World Aquaculture Society, v.29, n.3, p.319-324, 1998. 
DEDI, J.; TAKEUSHI, T.; SAIKAI, T. et al. Hypervitaminosis and safe levels of vitamin A for larval flounder (Paralichthys olivaceus) fed Artemia nauplii. Aquaculture , v.133, p.135-146, 1995.

FERREIRA, S.O. Aplicação de tecnologia a espécies de pescado de água doce visando atender a agroindústria rural. Piracicaba, 1987. 122p. Dissertação (Mestrado) Escola Superior de Agricultura 'Luiz de Queiroz”, Universidade de São Paulo.

FITZSIMMONS, K. Tilapia: The most important aquaculture species of the $21^{\text {st }}$ Century. In: INTERNATIONAL SYMPOSIUM OF TILAPIA IN AQUACULTURE 5., Rio de Janeiro, 2000. Anais. Rio de Janeiro: Panorama da Aqüicultura, 2000. v. 1, p.3-8.

FRACALOSSI, D.M. Doenças nutricionais em peixes. In: SIMPÓSIO SOBRE MANEJO E NUTRIÇÃO DE PEIXES 2., Campinas, 1998. Anais. Campinas: Colégio Brasileiro de Nutrição Animal, 1998. p. 97-122.

GOSWAMI, U.C.; DUTTA, N.K. Vitamin A-deficient diet and its effects on certain haematological parameters of Heteropneustes fossilis a 3-4 dehydroretinol rich freswater fish. International Journal of Vitamin Nutrition Research, v. 61, p.205-209, 1991.

GRAHAM, G.L.; JONES, J.H. The histopathologic features of vitamin A deficiency in a fish (Carassius auratus). Transactions of the American Microscopy Society, v.88, n. 1, p.168-169, 1969.

GRISDALE-HELLAND, B.; HELLAND, S.J.; ASGARD, T. Problems associated with the present use of menadione sodium bisulfite and vitamin $\mathrm{A}$ in diets for Atlantic salmon. Aquaculture, v.92, p.351-358, 1991.

HALVER, J.E. Recent advances in vitamin nutrition and metabolism in fish. In: COWEY, C.B.; MacKIE, A.M.; BELL, J.G. (Ed.). Nutrition and feeding in fish London: Academic Press, 1985. p.415-429.

HALVER, J.E. The vitamins. In: HALVER, J.E. (Ed.). Fish nutrition. 2.ed. San Diego: Academic Press, 1989. p.32-109. 
HARIKUMAR, P.; KAKATI, R.; GOSWAMI, U.C. Vitamin A-deficiency and its effects on the lysosomal enzymes of fish. International Journal of Vitamin Nutrition Research, v.66, p.97-100, 1996

HEPHER, B. Nutrition of pond fishes. Cambridge: Cambridge University Press, 1988. 388 p.

HOLE, S.M.; TAYLOR, K.D.A. Methods of extraction composition and stability of vitamin A and other components in dogfish (Squalus acanthias) liver oil. Food Chemistry, v.55, n.3, p.215-220, 1996.

KATSUYAMA, M.; MATSUNO, T. Carotenoid and vitamin A, and metabolism of carotenoids, $\beta$-carotene, canthaxanthin, astaxanthin, zeaxanthin, lutein and tunaxanthin, lutein and tunaxanthin in tilapia Tilapia Nilotica. Comparative Biochemistry and Physiology. v. 90B, n. 1, p. 131-139, 1988.

KUBITZA, F.; CYRINO, J.E.P. The effects of feed quality and feeding practices on the quality of fish: A Brazilian fish culture outlook. In CHANG, Y.K.; WANG, S.S. (Ed.). Advances in extrusion technology. Lancaster: Technomic Publ., 1999. p.5371.

KUBITZA, F.; CYRINO, J.E.P.; ONO, E.A. Rações comerciais para peixes no Brasil: situação atual e perspectivas. Panorama da Aqüicultura. v.8, n.50, p.38-49. 1998.

LALL, S.P.; PARAZO, M.P. Vitamins in fish and shellfish. In: RUITER, A. (Ed.). Fish and fishery products, composition, nutritive properties and stability. London: CAB Internacional, 1995. p.387.

LANDEN Jr; W.O.; EITENMILLER, R.R. Appliccation of gel permeation chromatography and nonaqueous reverse phase chromatography to high pressure liquid chromatographic determination of retinyl palmitate and $\beta$-carotene in oil and margarine. Journal of the Association of Official Analytical Chemists, v.62, n.2, p.283-289, 1979.

LANDOLT, M.L. The relationship between diet and the immune response of fish. Aquaculture, v. 79, p. 193-206, 1989. 
LATSCHA, T. Carotenoids in aquatic animal nutrition. In: AQUACULTURE FEED PROCESSINGS AND NUTRITION WORKSHOP, Singapore, 1991. Proceedings. Singapore: American Soybean Association, 1991.p. 68-79.

LEHNINGER, A L. Princípios de bioquímica. São Paulo: Sarvier, 1995. 839p

LOVELL, R.T. Diet and fish husbandry. In: HALVER, J.E. (Ed.). Fish nutrition. 2.ed. New York: Academic Press, 1989. p.549-603.

LOVELL, R.T. Nutrition of aquaculture species. Journal of Animal Science, v. 69, n.10, p. 4193-4200, 1991.

LOVELL, R.T. Nutrition and feeding of fish 2.ed. Boston: Kluwer Academic, 1998. $267 p$.

LOVSHIN, L.L. Tilapia Aquaculture in Brazil. In: COSTA-PIERCE, B.A.; RAKOCY, J.E. (Ed.). Tilapia aquaculture in the Americas 2. Baton Rouge: The World Aquaculture Society, 2000. p.133-140.

LUQUET, P. Tilapia, Oreochromis spp. In: WILSON, P.R. (Ed.). Handbook of nutrient requirements of finfish Boca Raton: CRC Press, 1991. p.208.

MADEN, M. Vitamin A in embryonic development. Nutrition Reviews, v.52, n.2, p.S3-S12, 1994.

McCARTHY, I. D.; GAIR D. J.; HOULIHAN, D. F. Feeding rank and dominance in Tilapia rendalli under defensible and indefensible patterns of food distribution. Journal of Fish Biology, v.55, n.4, p.854-867, 1999.

MIWA, S.; TAMANO, K. Retinoic acid stimulates development of adult-type chromatophores in the flounder. Journal of Experimental Zoology, v.284, p.317324, 1999.

MUNTZ, W.R.A. Observações adicionais sobre os pigmentos visuais e filtros amarelos nos olhos de peixes amazônicos. Acta Amazônica, v.11, n.1, p.113-123, 1981.

NATIONAL RESEARCH COUNCIL. Nutrient requirements of fish Washington: National Academic Press, 1993. 114 p.

OGATA, H.Y.; OKU, H. The effects of dietary retinoic acid on body lipid deposition in juvenile red sea bream (Pagrus major): a preliminary study. Aquaculture, v.193, p.271-279, 2001. 
ONG, D.E. Cellular transport and metabolism of vitamin A: roles of the cellular retinoid-binding proteins. Nutrition Reviews, v.52, n.2, p.S24-S 31, 1994.

ORNSRUD, R.; GRAFF, L.E.; HOIE, S. et al. Hypervitaminosis A in first-feeding fry of the Atlantic salmon (Salmo salar L.). Aquaculture Nutrition., v.8, n.1, p.7-13, 2002.

PEZZATO, L. E. O estabelecimento das exigências nutricionais das espécies de peixes cultivadas. In: SIMPÓSIO SOBRE MANEJO E NUTRIÇÃO DE PEIXES, Campinas, 1997. Anais .Campinas: CBNA, 1997. p. 45-55.

PEZZATO, L.E. Qualidade dos ingredientes, processamento e eficiência alimentar em aqüicultura. In: SIMPÓSIO BRASILEIRO DE AQUICULTURA, 12., Goiânia, 2002. Anais. Goiânia: UFG, 2002. p.116.

POSTON, H.A.; RIIS, R.C.; RUMSEY, G.L. et al. The effect of supplemental dietary amino acids, minerals and vitamins on salmonids fed cataractogenic diets. Cornell Veterinary, v. 67, p.472-509, 1977.

SALEH, G.; ELERAKU, W.; GROPP, J. M. A short note on the effects of vitamin A hypervitaminosis on health and growth of Tilapia nilotica (Oreochromis niloticus ). Journal of Applied Ichthyology, v.11, n.3/4, p.382-385, 1995.

SAS INSTITUTE. SAS / STAT 2001: user's guide: statistics version 8.2, (compact disc). Cary, 2001.

SILVA, S.S. de; ANDERSON, T.A. Fish nutrition in aquaculture. London: Chapman \& Hall, 1995. 319 p.

STEFFENS, W. Principles of fish nutrition. New York: Haslted Press; John Wiley, 1989. 384p.

TACON, A.G.J. Nutritional fish pathology. Rome: FAO, 1992. 75p. (FAO. Fisheries Technical Paper, 330).

TACON, A.G.J. Feed formulation and on-farm feed management. In NEW, M.B.; TACON, A.G.J.; CSAVAS, I. (Ed.). Farm-made aquafeeds. Rome: FAO, 1994. p.61-74. (FAO. Fisheries Technical Paper, 343). 
TAKEUCHI, T.; DEDI, J.; EBISAWA, C. et al. The effect of $\beta$-carotene and vitamin A enriched Artemia nauplii on the malformation and color abnormality of larval Japanese flounder. Fisheries Science, v. 61, n. 1, p. 141-148, 1995.

TAKEUCHI, T.; DEDI, J.; HAGA, Y. et al. Effect of vitamin A compunds on bone deformity in larval Japanese flounder (Paralichthys olivaceus). Aquaculture, v. 169, p. 155-165, 1998.

TAVEEKIJARAN, P.; MIYAZAKI, T.; MATSUMOTO, M. et al. Vitamin A deficiency in cherry salmon. Journal of Aquatic Animal Health, v.6, p.251-259, 1994.

THOMPSON, I.; CHOUBER, C.; HOULIHAN, D.F. et al. The effect of dietary vitamin A and astaxanthin on the immunocompetence of rainbow trout. Aquaculture, v.133, p.91-102, 1995.

TOGUYENI, A.; FAUCONNEAU, B.; BOUJARD, T. et al. Feeding behaviour and food utilization in tilapia, Oreochromis niloticus: effect of sex ratio and relationship with the endocrine status. Physiology \& Behaviour, v.62, n.2, p.273-279, 1997.

WEILER, R.; SCHULTZ, K.; JANSSEN-BIENHOLD, U. Retinoic acid induces vigorous spinule formation at the terminal dendrites of fish retinal horizontal cells. Investigative Ophthalmology \& Visual Science, v.38, n.4, p.S1164, 1997.

WEILER, R.; POTTEK, M.; HE, S. et al. Modulation of coupling between retinal horizontal cells by retinoic acid and endogenous dopamine. Brain Research Review, v.32, p.121-129, 2000. 